\title{
Proficiency in identifying, managing and communicating medical errors: feasibility and validity study assessing two core competencies
}

\author{
Abd Moain Abu Dabrh ${ }^{1,2^{*}}$ (D), Mohammad Hassan Murad ${ }^{1,2}$, Richard D. Newcomb ${ }^{1}$, William G. Buchta ${ }^{1}$, \\ Mark W. Steffen ${ }^{1}$, Zhen Wang ${ }^{2}$, Amanda K. Lovett ${ }^{1}$ and Lawrence W. Steinkraus ${ }^{1}$
}

\begin{abstract}
Background: Communication skills and professionalism are two competencies in graduate medical education that are challenging to evaluate. We aimed to develop, test and validate a de novo instrument to evaluate these two competencies.

Methods: Using an Objective Standardized Clinical Examination (OSCE) based on a medication error scenario, we developed an assessment instrument that focuses on distinctive domains [context of discussion, communication and detection of error, management of error, empathy, use of electronic medical record (EMR) and electronic medical information resources (EMIR), and global rating]. The aim was to test feasibility, acceptability, and reliability of the method.

Results: Faculty and standardized patients (SPs) evaluated 56 trainees using the instrument. The inter-rater reliability of agreement between faculty was substantial (Fleiss $k=0.71$ ) and intraclass correlation efficient was excellent $(I C C=0.80)$. The measured agreement between faculty and SPs evaluation of resident was lower (Fleiss $k=0.36)$. The instrument showed good conformity $(I C C=0.74)$. The majority of the trainees $(75 \%)$ had satisfactory or higher performance in all six assessed domains and $86 \%$ found the OSCE to be realistic. Sixty percent reported not receiving feedback on EMR use and asked for subsequent training.
\end{abstract}

Conclusion: An OSCE-based instrument using a medical error scenario can be used to assess competency in professionalism, communication, using EMRs and managing medical errors.

Keywords: Communication skills, Professionalism, Core competencies, Medical training, Medical errors, ACGME

\section{Background}

In 2001, the Accreditation Council for Graduate Medical Education (ACGME) defined six critical competencies in graduate medical education and mandated that resident-trainees be evaluated in those competencies [1]. Educators are particularly challenged in evaluating inter-personal and communication skills and professionalism, as assessing these two competencies might

\footnotetext{
* Correspondence: AbuDabrh.AbdMoain@mayo.edu

'Division of Preventive, Occupational, and Aerospace Medicine, Mayo Clinic, 200 First Street SW, Rochester, MN 55905, USA

${ }^{2}$ The Evidence-based Practice Center, Mayo Clinic Robert D. and Patricia E.

Kern Center for the Science of Health Care Delivery, Rochester, MN, USA
}

be influenced by various factors, including perception and social factors [2]. Both cores have been mostly measured through using multiple evaluators (e.g., faculty, peers) and through role-playing scenarios to provide subjective nonstandardized feedback on performance [3]. Optimally, educators are able to demonstrate that graduating residents are competent in appropriate use of medical records, effective communication with patients, and effective communication with other healthcare professionals. Resident-trainees also need to demonstrate integrity, ethical behavior, accept responsibility, follow through on tasks, and demonstrate care and concern for patients [4]. 
Several of the elements described in the definitions of these two competencies can be assessed in a clinical encounter in which residents interact with the electronic medical record (EMR) and electronic medical information resources (EMIR), identify a medical error, communicate to the patient that an error has occurred, and provide a plan for corrective action. This scenario is not rare. Medical errors are very common and have been recognized as a major cause of morbidity, mortality and increased health expenditure [5]. Similarly, the use of EMRs is becoming a standard of care in the US. Patient safety concerns, cost-effectiveness research, and medicolegal pressures have all contributed to the drive for healthcare providers to acquire and effectively use EMRs [6-8]. The ability to rapidly and accurately access patient medical data and communicate medical data to patients can be lifesaving. Competency in using EMRs has been recently even more emphasized through the Meaningful Use Incentive Program by the Centers for Medicare and Medicaid Services [9]. The special skills required to identify and communicate an error are closely tied to both competencies; inter-personal and communication skills, as well as professionalism. These two competencies can be evaluated using the traditional methods of direct faculty observation and global assessment. However, newer methods that include simulation, the use of standardized patients (SPs) and Objective Structured Clinical Examinations (OSCEs) are particularly important in this context. Studies have reported using OSCE to evaluate professionalism [10], communication and both competencies combined [11, 12]. OSCEs have been used to teach and evaluate communication of adverse outcomes and medical errors [11, 13]. Calls for establishing and documenting competency in using EMRs have also been made by the American Medical Informatics Association and others who highlighted the impact of such competency on patient safety and quality of care [14, 15]. Although several studies found OSCE valid and reliable in various settings [16-19]; others found it not fully reliable with variable results across the six competencies [20].

The ACGME's Residency Review Committee agreed that the initial measurement tools they developed to assess the ACGME Competencies should be revised [21]. Although many tools are available, the validity evidence, direction and educational outcomes of the majority of them are lacking [22]. In response, we planned to develop and use a de novo assessment instrument combined with an OSCE-like scenario as a tool in which SPs and faculty evaluate medical residents' ability to use the EMR and available EMIRs to detect a medical error, communicate this error to patients and provide corrective action. We hypothesized that the use of this medical error-centered scenario would be a feasible and acceptable tool for testing the two competencies of professionalism and, interpersonal and communication skills. We also tested for the agreement and reliability of this instrument using different faculty and standardized patients during simulation training.

\section{Methods}

\section{Setting and participants}

The study was conducted at the Mayo Clinic-Rochester, a tertiary care academic center in Minnesota. The study designed as a single-station OSCE-based simulation assessment scenario. Fifty-six participants were mainly first- (PGY1), second- (PGY2) and third-year (PGY3) Internal Medicine residents doing a rotation in Preventive Medicine and Public Health, and second-year fellows in Preventive Medicine. Additionally, the study included 10 medical students $\left(4^{\text {th }}\right.$ Year MS), and eight preventive medicine fellows (PGY4 and 5). All trainees (except med students) had received orientation and training on using the EMR and had completed at least an internship year using this EMR. This simulation activity is considered by trainees as an expected regular departmental training event within didactic educational activities and clinical training or rotations; hence, trainees were not informed about the purpose of this scenario in order to achieve blinding and we did not pursue any specific sampling methodology. Each scenario was observed by preventive medicine faculty via closed circuit TV in a dedicated simulation center. Videos were captured using a secure server for concurrent or subsequent faculty viewing for duplicate evaluation. Screen shots demonstrating websites (EMIRs) visited by resident during the encounter were saved. The Information Technology Specialists and the simulation center staff created a safe electronic environment that allowed residents to access the EMR of the SP that was identical to a chart seen in usual practice. Additionally, we visually measured the time trainees spent using EMR and EMIR before meeting the SPs and during encounter, and recorded the resources (e.g. websites) they used during this training.

The study initially started with proof of concept, instrument refinement, and feasibility stages, testing the instrument on 15 residents who were assessed by 4 faculty members (AMAD, LS, MHM, RN) and one SP.

\section{Standardized patients (SPs) and observing faculty}

Trained standardized patients participated in this scenario. These SPs have extensive experience in roleplaying multiple scenarios at the simulation center. The study investigators developed the scenario and revised and reviewed it for accuracy, realism, acceptability by faculty as well as the feedback from SPs and the pilot group of 15 residents. Faculty received training on medical simulation with SPs, debriefing techniques and the 
use of performance checklist and global assessment instruments. Eventually, six faculty members evaluated all 56 trainees. One faculty observed the scenario in real time and provided an evaluation at the conclusion of OSCE. One of the other five faculty members subsequently reviewed the video of the same encounter, blinded to the previous rating, and provided a rating of each resident using the same instrument.

Preparatory to the OSCE, trainees received didactic and small group training on blood and body fluid exposure procedures, communication in healthcare, recommendations on use of EMR/EMIR resources, and medical error as part of their Preventive Medicine and Internal Medicine curricula. An electronic curriculum was also available as a resource and a required/recommended reading list was provided to each trainee at the beginning of their Preventive Medicine rotation.

\section{Encounter scenario}

The scenario entailed the SP presenting as a registered nurse who has worked full time at the Emergency Department (ED) for 20 years. The nurse has been generally quite healthy and visits the clinic that day for counseling after a needle-stick incident that took place the previous day while caring for a patient with a low viral load of Human immunodeficiency virus (HIV). She had screening labs drawn and was started on postexposure prophylaxis for 4 weeks per CDC guidelines. The nurse reports extreme fatigue and difficulty staying alert. She brought her medications in because she is concerned about side effects that might warrant a change in the regimen. She presents the trainee with two bottles of Lamivudine, Zidovudine (Combivir ${ }^{\circ}$ ) and Levetiracetam (Keppra ${ }^{\circ}$ ). The trainee is expected to consider a medication error because Keppra is not used for HIV prophylaxis and to realize that another drug with a similar name was intended to be prescribed, (Kaletra ${ }^{\circ}$ (Lopinavir and Ritonavir)). The Keppra-Kaletra dispensing error is a recognized error according to the FDA [23, 24]. The trainee has access to a simulated EMR that is not in a production environment and to standard web resources/EMIRs to help in identifying the medication and describe drug interactions and side effects. The trainees are instructed to perform an initial history, exam and discussion. They are told that, as in the clinic, they can leave the room to staff the patient with faculty, discuss the case with the faculty, and then return to the room to dismiss the patient and provide instructions about management and follow up. Finally, they debrief with faculty.

\section{Assessment instrument}

This Instrument for Communication skills and Professionalism Assessment (InCoPrA) was developed, reviewed, pilot-tested, and revised by the study investigators, taking into consideration the ACGME definition of competencies and existing tools used for other OSCE scenarios and competencies evaluation $[21,25,26]$ and the feedback provided during the pilot testing. Professionalism was defined as the commitment to carrying out professional responsibilities and an adherence to ethical principles with integrity, compassion, honesty and respect while responding to patients' needs and managing their healthcare appropriately. Interpersonal and communication skills were defined as the ability to effectively communicate clearly, directly, thoroughly and responsibly with the patients, their families, and healthcare team members while maintain comprehensive knowledge of medical records and pertinent information.

The instrument piloting process had three forms or parts; 1) evaluation of trainees by Faculty; 2) evaluation of trainees by SP; and 3) trainee self-administered survey. The faculty and SP instrument forms use a 3-point Likertlike scale for the different questions (outstanding; satisfactory; and unsatisfactory). Six domains are addressed in the SP and faculty assessments (the context of discussion, communication and detection of error, management of the error, empathy, use of EMR and EMIR, and a global rating). Faculty and SPs are provided with a manual for the instrument that suggests questions/checklist of items that can be used to rate each category. The instrument is included with the oneline-only material (Additional file 1).

The self-evaluation survey by residents consists of asking them about how they self-rate their general skills of EMR and EMIR use, and then rating their performance after the encounter for comparison. Also, they are asked to rate how realistic the medical error scenario encounter felt, how comfortable they were using EMR and EMIR during the encounter, and how often they receive feedback from someone during their current training on the use of such resources. Additionally, they were asked to disclose if they received training using EMR or EMIR during medical school and/or residency, if they think it is helpful to receive more training, and if yes, which level they think it might be helpful.

\section{Statistical analyses}

The pilot phase of this study was to demonstrate the acceptability and feasibility of this assessment instrument (15 residents). Later on, and after adding 41 trainees, we evaluated the inter-observer agreement to determine reproducibility, conformity and consistency between the raters (faculty and SPs) overall and over each domain. We conducted descriptive analyses and presented rates, means, and range for each item/domain where pertinent. To evaluate the inter-rater agreement, we used Fleiss' kappa [27], in which $0.21-0.40$ suggests fair agreement, 0.41-0.60 moderate agreement, $0.61-0.80$ substantial 
agreement, and $>0.81$ almost perfect agreement. We also calculated the intra-class correlation coefficient (ICC) using 2-way random-effects models. ICC $<0.40$ can be interpreted as poor, $0.40-0.75$ as fair to good, and $>0.75$ as excellent. All analyses were conducted using Stata version 14.0 (StataCorp LP, College Station, TX).

We described the use and statistics of EMR/EMIR usage, and trainee self-evaluation survey results were collected and presented using descriptive statistics.

\section{Human subject protection}

The Mayo Clinic Institutional Review Board (IRB) approved the study as an educational intervention required by the respective training programs and considered it to be IRB-exempt study (45 CFR 46.101, item 1). This simulation activity is considered as an expected regular departmental training event within the didactic clinical educational activities and training, therefore no specific participation consent deemed required. The Mayo Clinic Simulation Center obtained standard consents for observation for all trainees per institutional guidelines. Additionally, the study authors and coordinators obtained standard consent for observation for all trainees per institutional guidelines.

\section{Results}

In the pilot phase, faculty and SPs evaluated 15 trainees using the instrument. Table 1 summarizes the pilot results. In addition to the training we provided to our SP's and faculty initially, the pilot stage served to provide feedback to our experience before enrolling more trainees.

After enrolling all 56 trainees, the majority of the trainees $(75 \%)$ had satisfactory or higher performance in all six assessed domains as shown in Table 2. The range of time spent in encounters ranged between14$47 \mathrm{~min}$. In testing the reliability of the instrument, the inter-rater agreement between faculty members was substantial (Fleiss $\mathrm{k}=0.71$ ) and intraclass correlation efficient showed strong conformity among faculty (ICC $=0.8$ ). The measured agreement between faculty and SPs were fair (Fleiss $\mathrm{k}=0.39$ ). The instrument showed moderate robustness (Pearson $r=0.43$ ) and good conformity $(\mathrm{ICC}=0.74)$.

\section{EMR and EMIR usage}

We collected the usage data of 46 trainees. Twentyseven trainees opted to use EMIR to further find helpful resources while 19 trainees did not access any online resources. Eighteen of the 27 trainees used more than one resource to seek further helpful information. For those who identified the medical error (35 trainees), the average time spent using EMR before entering the room was $3 \mathrm{~min}$ and $23 \mathrm{~s}$ (based on 28/35 trainees) while they spent $80 \mathrm{~s}$ during the encounter (based on $35 / 35$ trainees) using EMR.

For those who missed the medical error (11 trainees), the average time spent using EMR before entering the room was $2 \mathrm{~min}$ (based on $7 / 11$ trainees) while $2 \mathrm{~min}$ and $41 \mathrm{~s}$ were spent during the encounter with a total

Table 1 Pilot results summary of SPs and faculty evaluation on the six domains of the instrument

\begin{tabular}{|c|c|c|c|}
\hline Category & SP assessment & Category & Faculty assessment \\
\hline \multirow[t]{3}{*}{ Context for discussion } & $73 \%$ outstanding & Context for discussion & $85 \%$ outstanding \\
\hline & $18 \%$ satisfactory & & $15 \%$ satisfactory \\
\hline & $9 \%$ unsatisfactory & & $0 \%$ unsatisfactory \\
\hline \multirow[t]{3}{*}{ Communication and Management } & $64 \%$ outstanding & Communication of detection of error & $61 \%$ outstanding \\
\hline & $36 \%$ satisfactory & & $31 \%$ satisfactory \\
\hline & $0 \%$ unsatisfactory & & $8 \%$ unsatisfactory \\
\hline \multirow[t]{3}{*}{ Empathy } & $73 \%$ outstanding & Management of error & $62 \%$ Outstanding \\
\hline & $18 \%$ satisfactory & & $23 \%$ satisfactory \\
\hline & $9 \%$ unsatisfactory & & $15 \%$ unsatisfactory \\
\hline \multirow[t]{3}{*}{ Honesty and Truthfulness } & $82 \%$ outstanding & Empathy & 77 \% Outstanding \\
\hline & $18 \%$ satisfactory & & $23 \%$ satisfactory \\
\hline & $0 \%$ unsatisfactory & & $0 \%$ unsatisfactory \\
\hline \multirow[t]{3}{*}{ Closure } & $85 \%$ outstanding & Use of EMR and EMIR & $62 \%$ Outstanding \\
\hline & $15 \%$ satisfactory & & $38 \%$ satisfactory \\
\hline & $0 \%$ unsatisfactory & & $0 \%$ unsatisfactory \\
\hline \multirow[t]{3}{*}{ Global rating } & $56 \%$ outstanding & Global rating & 77 \% Outstanding \\
\hline & $36 \%$ satisfactory & & $16 \%$ satisfactory \\
\hline & $18 \%$ unsatisfactory & & $7 \%$ unsatisfactory \\
\hline
\end{tabular}


Table 2 Final summary of results of SPs and faculty evaluation on the six domains of the instrument

\begin{tabular}{|c|c|c|c|}
\hline Category & SP assessment ${ }^{a}$ & Category & Faculty assessment \\
\hline \multirow[t]{3}{*}{ Context for discussion } & $46 \%$ outstanding & Context for discussion & $40 \%$ outstanding \\
\hline & $33 \%$ satisfactory & & $57 \%$ satisfactory \\
\hline & $20 \%$ unsatisfactory & & $3 \%$ unsatisfactory \\
\hline \multirow[t]{3}{*}{ Honesty and Truthfulness } & $63 \%$ outstanding & Communication of detection of error & $41 \%$ outstanding \\
\hline & $22 \%$ satisfactory & & $32 \%$ satisfactory \\
\hline & $15 \%$ unsatisfactory & & $27 \%$ unsatisfactory \\
\hline \multirow[t]{3}{*}{ Empathy } & $56 \%$ outstanding & Empathy & $77 \%$ Outstanding \\
\hline & $39 \%$ satisfactory & & $32 \%$ satisfactory \\
\hline & $5 \%$ unsatisfactory & & $1 \%$ unsatisfactory \\
\hline \multirow[t]{3}{*}{ Closure } & $43 \%$ outstanding & Management of error & $62 \%$ Outstanding \\
\hline & $44 \%$ satisfactory & & $23 \%$ satisfactory \\
\hline & $13 \%$ unsatisfactory & & $15 \%$ unsatisfactory \\
\hline \multirow[t]{6}{*}{ Global rating } & $48 \%$ outstanding & Use of EMR and EMIR & $43 \%$ Outstanding \\
\hline & $39 \%$ satisfactory & & $39 \%$ satisfactory \\
\hline & $13 \%$ unsatisfactory & & $13 \%$ unsatisfactory \\
\hline & & Global rating $^{c}$ & $29 \%$ Outstanding \\
\hline & & & $46 \%$ satisfactory \\
\hline & & & $25 \%$ unsatisfactory \\
\hline
\end{tabular}

${ }^{a}$ Data were not available for 3 trainees

${ }^{b}$ Data were not available for 3 trainees

${ }^{\mathrm{C}}$ Data were not available for 1 trainee

average of $127 \mathrm{~s}$ (based on 11/11 trainees) using EMR. Summary of results is shown in Table 3.

\section{Trainees/residents self rating}

After finishing each encounter, 47 trainees (84 \%) returned the survey about their experience and their use of EMR and EMIR. Thirty-three trainees (70 \%) found the scenario to be realistic and significantly resembling real-life scenario. While 34 of the trainees (72 \%) reported receiving training on the use of EMR during residency and/or medical school training and considered themselves to have above average experience with EMR and EMIR, only 13 of them (38\%) rated their own performance that day to be matching to their self-rated experience. Twenty-eight trainees $(60 \%)$ reported the lack of feedback from staff members, senior residents or

Table 3 Summary of EMR/EMIR usage ${ }^{a}$

\begin{tabular}{|c|c|c|}
\hline & $\begin{array}{l}\text { Detected medical error group } \\
\text { ( } 35 \text { trainees) } \\
\text { Time } \Omega \text { ( } \mathrm{N} \text { of trainees based on) }\end{array}$ & $\begin{array}{l}\text { Did not detect medical error } \\
\text { ( } 11 \text { trainees) } \\
\text { Time } \Omega \text { ( } \mathrm{N} \text { of trainees based on) }\end{array}$ \\
\hline Average time spent using EMR before meeting SP & $03: 23(28)$ & $02: 00(7)$ \\
\hline Average time spent using EMR during encounter & $01: 20(35)$ & 2:41 (11) \\
\hline Average time spent using EMR (combined) & 01:58 (28) & 02:07 (7) \\
\hline Average time spent using EMIR & $02: 22(35)$ & $00: 52(10)$ \\
\hline EMIR use during encounter & $\begin{array}{l}\text { None (18) } \\
\text { Yes (17) } \\
\text { o Micromedex }{ }^{\circledR}(14) \\
\text { o UpToDate } \\
\text { o Google }{ }^{\circledR}(8) \\
\text { o Aids.gov }{ }^{\circledR}(4) \\
\text { o } \text { CDC }^{\text {b }}(3) \\
\text { o WHO } \\
\text { o Wikipedia }{ }^{\circledR}(2) \\
\text { o Other sources (4) }\end{array}$ & $\begin{array}{l}\text { None (9) } \\
\text { Yes }(2) \\
\text { o Micromedex }{ }^{\circledast}(1) \\
\text { o Google } \\
\text { o MedicineNet }{ }^{\oplus}(1)\end{array}$ \\
\hline
\end{tabular}


fellows about their experience with access to EMR. Nineteen trainees (40 \%) stated that it will be helpful to receive short post-internship re-training courses or sessions.

\section{Discussion}

In this study, we developed, piloted and tested the reliability of an OSCE-based instrument to evaluate professionalism and communication using a medical error scenario. The majority of residents were found by faculty and SPs to have satisfactory or higher performance in six relevant domains (the context of discussion, communication and detection of error, management of the error, empathy, use of EMR and EMIR and a global rating). The instrument showed substantial agreement and conformity between faculty raters but a fair to moderate reliability between faculty and SPs.

The majority of residents found the OSCE to be realistic. Although most of the residents received prior training in using EMR, the majority reported lack of feedback and asked for subsequent training.

Professionalism and communication are highly important for healthcare professionals to perform, evolve and establish provider-patient, as well provider-provider, relationships. The proficiency in these two competencies, however, is challenging to assess. Mazor et al. [10] highlighted the complexity of evaluating professionalism using qualitative and quantitative analyses and concluded the need for models that assess and address the inter-rater reliability and diversity in viewing professionalism. Medical simulation has become an accepted means of safely training healthcare providers and preparing them for real life scenarios; examples include physical examination and interviewing skills, procedural testing, and communication of test results or clinical recommendations. With The Next GME Accreditation System being implemented [28], there will be more emphasis on explicit evaluation of discrete milestones and achievement of predefined levels of proficiency. Therefore, developing a valid instrument is paramount. Validity of assessment in itself is contextual and could also be subject to bias of performance, learner, domain, and the interpretation of decisions made based on the assessment data [29]; nonetheless, validity is a reliable measure of sufficient performance and provides an accurate support of evidence to the assessed scenario, and it is widely missing from pre-existing assessment tools [22].

The OSCE assessment has been established as a reliable instrument to assess trainee-residents clinical skills and patient care knowledge. Varkey et al. [30] concluded that it can also be a powerful tool to assess two other competencies, Systems-Based Practice and PracticeBased Learning and Improvement. Short et al. [31] found OSCEs to have a measureable value to assess performance improvement between trainees coming into (incoming/pre-internship) and graduating (outgoing/ post-internship) from a program by the end of the year to evaluate program effectiveness on all six competencies. OSCEs have also been found to weakly correlate with the United State Medical Licensing Examination (USMLE) scores in assessing medical graduates skills and knowledge [32]. When Short et al. [31] evaluated OSCEs at the beginning and the end of training; they noted that the improved outcome results might be affected by "retake bias" and familiarity. They also questioned OSCEs' ability to fully test current actual performance. Further, OSCEs may not necessarily address the shortages the "incoming" testers had in competencies. Using various scenarios to test and evaluate competencies may also introduce bias by confounding with inherent characteristics of each scenario.

In our study, we used one scenario in an attempt to standardize these characteristics although this may cause contamination if trainees took the OSCE and then informed other trainees of upcoming scenarios. Stroud et al. [33] found that using such methodology and scenario did not result in significant differences in performance among their tested residents. The degree of difference between SPs and faculty is expected, as patients may look at things from a different perspective, providing an excellent opportunity for feedback from patients regarding aspects training clinicians can improve upon. Other challenges exist. We realize that generalization of the assessment we conducted in our study to other institutions will be limited by availability of resources, faculty training and information technology infrastructure. Educators and trainees may focus on clinical knowledge and patient care and put lower emphasis on the other competencies. Our study is the first in the U.S. to exclusively assess these two important core competencies through a medical error scenario and to evaluate the use of EMR/ EMIR in depth. The use of medical error scenario is a standard practice with noted reliable results in educating and training postgraduate trainees, and our results affirm such findings while minimizing subjective evaluations [33]. The availability of enhancing resources, such as videotaping and simultaneous screenshots, provided an opportunity to assess inter-rater agreement and reliability of the instrument, revisit performance, confirm results, and possibly examine other variables of interest. Furthermore, this work can be extended in future interventional studies that aim at improving proficiency in professionalism, communication, using EMRs/EMIRs and managing medical errors, as well as educating both, faculty and trainees, about standard practices, including detection of medical errors, and providing opportunities for early detection of under-performers, creating opportunities and encouraging feedback for improvements, and recognizing the well-achievers. 


\section{Conclusion}

An OSCE-based instrument using a medical error scenario can be used to assess proficiency in professionalism, communication, using EMRs and managing medical errors, and provides significant feedback for the purpose of identifying areas to worm on, improve and help in directing future goals.

\section{Additional file}

Additional file 1: Instrument for Communication skills and Professionalism Assessment (InCoPrA). A copy of the two parts of the assessment instrument that include the Faculty Evaluation of Learner component and the Standardized Patient (SP) Evaluation of Learner forms. (DOC $44 \mathrm{~kb}$ )

\section{Acknowledgements}

The authors would like to thank the Simulation Center staff at Mayo Clinic in Rochester, MN, especially, Mr. Thomas E. Belda and Mr. Todd J. Summerson, for their incredible efforts and help to make this study possible.

\section{Funding}

Not applicable.

\section{Availability of data and materia}

The authors have full access to all the data in the study and take responsibility for the integrity of the data and the accuracy of the data analysis. The data are available from the corresponding author on reasonable request.

\section{Authors' contributions \\ All authors of the manuscript have read and agreed to its content and are accountable for all aspects of the accuracy and integrity of the manuscript in accordance with ICMJE criteria. All authors have given final approval of the version to be published. AMAD: Co-led the study, part of the experts panel in building the instrument and study designing, supervised the encounters guidelines adherence and quality, data output, participated in the analytic plan statistics, and drafted the manuscript. MHM: Part of the experts panel in building the instrument and study designing, participated in the analytic plan statistics, revised the manuscript, and study faculty panel member. RDN: Part of the experts panel in building the instrument and study designing, revised the manuscript, and study faculty panel member. WGB: Part of the experts panel in building the instrument and study designing, revised the manuscript, and study faculty panel member. MWS: Data output and analysis, revised the manuscript, and study faculty panel member. ZW: Data output, led the analytic plan and statistics, and revised the manuscript. AKL: Data collection and data output, residents participation preparation, revised the manuscript and co-supervised in running the encounters. LWS: Co-led the study, revised the instrument, part of the experts panel in building the instrument, and study faculty panel member.}

\section{Authors' information}

AMAD: Assistant Professor of Medicine, Research Associate, Preventive Medicine.

MHM: Program Director, Preventive Medicine Residency.

RDN, WGB and MWS: Faculty, Preventive Medicine.

AKL: Program Education Coordinator

ZW: Associate Consultant, Health Services Research.

LWS: Program Director, Aerospace Medicine.

\section{Competing interests}

The authors declare that they have no competing interests.

\section{Consent for publication}

Not applicable.

\section{Ethics approval and consent to participate}

The Mayo Clinic Institutional Review Board (IRB) approved the study as an educational intervention required by the respective training programs and considered it to be IRB-exempt study (45 CFR 46.101, item 1). This simulation activity is considered as an expected regular departmental training event within the didactic clinical educational activities and training, therefore no specific participation consent deemed required. The Mayo Clinic Simulation Center obtained standard consents for observation for all trainees per institutional guidelines. Additionally, the study authors and coordinators obtained standard consent for observation for all trainees per institutional guidelines.

Received: 6 April 2016 Accepted: 24 August 2016

Published online: 02 September 2016

\section{References}

1. The Accreditation Council for Graduate Medical Education (ACGME) [http:// www.acgme.org]. Accessed 4 May 2015.

2. Hodges BD, Ginsburg S, Cruess R, Cruess S, Delport R, Hafferty F, Ho MJ, Holmboe E, Holtman M, Ohbu S, et al. Assessment of professionalism: recommendations from the Ottawa 2010 Conference. Med Teach. 2011; 33(5):354-63.

3. Ratanawongsa N, Bolen S, Howell EE, Kern DE, Sisson SD, Larriviere D. Residents' perceptions of professionalism in training and practice: barriers, promoters, and duty hour requirements. J Gen Intern Med. 2006;21(7):758-63.

4. Swing SR. The ACGME outcome project: retrospective and prospective. Med Teach. 2007;29(7):648-54.

5. To Err is Human: Building A Safer Health System - Institute of Medicine [http://www.nationalacademies.org/hmd/Reports/1999/To-Err-is-HumanBuilding-A-Safer-Health-System.aspx]. Accessed 4 May 2015.

6. Stewart WF, Shah NR, Selna MJ, Paulus RA, Walker JM. Bridging the inferential gap: the electronic health record and clinical evidence. Health Aff (Millwood). 2007;26(2):w181-91.

7. Coiera E, Hovenga EJ: Building a sustainable health system. Yearb Med Inform 2007:11-18.

8. Kukafka R, Ancker JS, Chan C, Chelico J, Khan S, Mortoti S, Natarajan K, Presley K, Stephens K. Redesigning electronic health record systems to support public health. J Biomed Inform. 2007:40(4):398-409.

9. EHR Incentive Programs, The Official Web Site for the Medicare and Medicaid Electronic Health Records (EHR) Incentive Programs [http://www. cms.gov/Regulations-and-Guidance/Legislation/EHRIncentivePrograms/ index.html?redirect=/ehrincentiveprograms/]. Accessed 4 May 2015.

10. Mazor KM, Zanetti ML, Alper EJ, Hatem D, Barrett SV, Meterko V, Gammon W, Pugnaire MP. Assessing professionalism in the context of an objective structured clinical examination: an in-depth study of the rating process. Med Educ. 2007:41(4):331-40.

11. Posner G, Nakajima A. Assessing residents' communication skills: disclosure of an adverse event to a standardized patient. J Obstet Gynaecol Can. 2011; 33(3):262-8.

12. Hochberg MS, Kalet A, Zabar S, Kachur E, Gillespie C, Berman RS. Can professionalism be taught? Encouraging evidence. Am J Surg. 2010;199(1): 86-93.

13. Varkey P, Natt N. The Objective Structured Clinical Examination as an educational tool in patient safety. Jt Comm J Qual Patient Saf. 2007;33(1): $48-53$.

14. Bernd DL, Fine PS. Electronic medical records: a path forward. Front Health Serv Manage. 2011;28(1):3-13.

15. Kamath J, Storlie D, Ferguson J: EMR competency: supporting quality, safe and effective care. AMIA Annu Symp Proc. 2006:974

16. Carraccio C, Englander R. The objective structured clinical examination: a step in the direction of competency-based evaluation. Arch Pediatr Adolesc Med. 2000;154(7):736-41.

17. Ositadimma ON, Che'an A, Nora A, Rosnida AB: Assessing Nursing Clinical Skills Competence through Objective Structured Clinical Examination (OSCE) for Open Distance Learning Students in Open University Malaysia. Contemp Nurse. 2012:41(2):233-241.

18. Petrusa ER, Blackwell TA, Ainsworth MA. Reliability and validity of an objective structured clinical examination for assessing the clinical performance of residents. Arch Intern Med. 1990;150(3):573-7. 
19. Tudiver F, Rose D, Banks B, Pfortmiller D. Reliability and validity testing of an evidence-based medicine OSCE station. Fam Med. 2009;41(2):89-91.

20. Brannick MT, Erol-Korkmaz HT, Prewett M. A systematic review of the reliability of objective structured clinical examination scores. Med Educ. 2011;45(12):1181-9.

21. Chipman JG, Beilman GJ, Schmitz CC, Seatter SC. Development and pilot testing of an OSCE for difficult conversations in surgical intensive care. J Surg Educ. 2007;64(2):79-87.

22. Kogan JR, Holmboe ES, Hauer KE. Tools for direct observation and assessment of clinical skills of medical trainees: a systematic review. JAMA. 2009;302(12):1316-26.

23. Drug Products Associated with Medication Errors [http://www.fda.gov/ drugs/drugsafety/medicationerrors/ucm286522.htm]. Accessed 4 May 2015.

24. Saftey Alerts for Human Medical Products [http://www.fda.gov/downloads/ Safety/MedWatch/Safetylnformation/SafetyAlertsforHumanMedicalProducts/ UCM168792.pdf]. Accessed 4 May 2015.

25. Tabuenca A, Welling R, Sachdeva AK, Blair PG, Horvath K, Tarpley J, Savino JA, Gray R, Gulley J, Arnold T, et al. Multi-institutional validation of a webbased core competency assessment system. J Surg Educ. 2007;64(6):390-4.

26. Chan DK, Gallagher TH, Reznick R, Levinson W. How surgeons disclose medical errors to patients: a study using standardized patients. Surgery. 2005:138(5):851-8.

27. Hale CA, Fleiss JL. Interval estimation under two study designs for kappa with binary classifications. Biometrics. 1993:49(2):523-34.

28. Nasca TJ, Philibert I, Brigham T, Flynn TC. The next GME accreditation system-rationale and benefits. N Engl J Med. 2012;366(11):1051-6.

29. Andreatta PB, Marzano DA, Curran DS. Validity: what does it mean for competency-based assessment in obstetrics and gynecology? Am J Obstet Gynecol. 2011;204(5):384. e381-386.

30. Varkey P, Natt N, Lesnick T, Downing S, Yudkowsky R. Validity evidence for an OSCE to assess competency in systems-based practice and practicebased learning and improvement: a preliminary investigation. Acad Med. 2008;83(8):775-80.

31. Short MW, Jorgensen JE, Edwards JA, Blankenship RB, Roth BJ. Assessing intern core competencies with an objective structured clinical examination. J Grad Med Educ. 2009;1 (1):30-6.

32. Dong T, Saguil A, Artino Jr AR, Gilliland WR, Waechter DM, Lopreaito J, Flanagan A, Durning SJ. Relationship between OSCE scores and other typical medical school performance indicators: a 5-year cohort study. Mil Med. 2012;177(9 Suppl):44-6.

33. Stroud L, Mcllroy J, Levinson W. Skills of internal medicine residents in disclosing medical errors: a study using standardized patients. Acad Med. 2009;84(12):1803-8.

\section{Submit your next manuscript to BioMed Central and we will help you at every step:}

- We accept pre-submission inquiries

- Our selector tool helps you to find the most relevant journal

- We provide round the clock customer support

- Convenient online submission

- Thorough peer review

- Inclusion in PubMed and all major indexing services

- Maximum visibility for your research

Submit your manuscript at www.biomedcentral.com/submit

) Biomed Central 